\title{
A macrophage and theca cell-enriched stromal cell population influences growth and survival of immature murine follicles in vitro
}

\author{
Candace M Tingen ${ }^{1,2}$, Sarah E Kiesewetter ${ }^{1}$, Jennifer Jozefik ${ }^{1}$, Cristina Thomas ${ }^{1}$, David Tagler ${ }^{3,4}$, \\ Lonnie Shea $^{3,4}$ and Teresa K Woodruff ${ }^{1,2}$ \\ ${ }^{1}$ Department of Obstetrics and Gynecology and ${ }^{2}$ Institute for Women's Health Research, Feinberg School of Medicine, \\ Northwestern University, 303 E Superior Street, Chicago, Illinois 60611, USA and Departments of ${ }^{3}$ Chemical and \\ Biological Engineering and ${ }^{4}$ Biomedical Engineering, Northwestern University, Evanston, Illinois 60208, USA
}

Correspondence should be addressed to T K Woodruff at Department of Obstetrics and Gynecology, Feinberg School of Medicine, Northwestern University; Email: tkw@northwestern.edu

\begin{abstract}
Innovations in in vitro ovarian follicle culture have revolutionized the field of fertility preservation, but the successful culturing of isolated primary and small secondary follicles remains difficult. Herein, we describe a revised 3D culture system that uses a feeder layer of ovarian stromal cells to support early follicle development. This culture system allows significantly improved primary and early secondary follicle growth and survival. The stromal cells, consisting mostly of thecal cells and ovarian macrophages, recapitulate the in vivo conditions of these small follicles and increase the production of androgens and cytokines missing from stromal cell-free culture conditions. These results demonstrate that small follicles have a stage-specific reliance on the ovarian environment, and that growth and survival can be improved in vitro through a milieu created by pre-pubertal ovarian stromal cell co-culture.

Reproduction (2011) 141 809-820
\end{abstract}

\section{Introduction}

The ability to culture ovarian follicles in vitro is an important step towards preserving fertility for women who would like to delay childbearing or for cancer patients, whose gametes can be damaged by cancer therapeutics (Jeruss \& Woodruff 2009). In vitro follicle culture also provides an ideal environment to investigate the effects of extra-follicular hormones, gonadotropins, paracrine factors, intraovarian molecules, and nonfollicle cells on the maturation of follicles and oocytes.

Current in vitro follicle culture systems vary widely; they can involve plating on a flat surface, encapsulation in a 3D matrix, or alternative culture conditions that prevent the follicle from adhering to a surface, such as culture with constant orbital rotation (reviewed in Picton et al. (2008) and Smitz et al. (2010)). Our group has pioneered a 3D culture environment that surrounds the follicles with alginate, a biologically inert molecule derived from seaweed that gels in the presence of calcium and can be degraded very quickly by alginate lyase (Pangas et al. 2003, Rinaudo 2008). This culture system has provided the context from which live births in the mouse have been achieved, starting from pre-antral follicles isolated and grown in vitro (Xu et al. 2006a).
More recently, we have successfully cultured follicles from both the non-human primate and human, from the secondary/pre-antral stage to the antral stage for both species (Xu et al. 2009a, 2009b). The alginate hydrogel culture system still has limitations, however, as primordial, primary, or small secondary follicles $(\leq 120 \mu \mathrm{m}$ in starting size) do not grow. These small stages have been the black box of follicle culture for the history of the process; the only successful technique for culture of these follicles involves the two-step processes of first culturing small follicles in either ovarian tissue chunks or liquid droplets before transferring the surviving, larger follicles to more long-term culture conditions (Liu et al. 2001, O'Brien et al. 2003, Adriaens et al. 2004, Lenie et al. 2004). Culturing the small follicle through antral follicle development in a single step, where conditions are not changed through the duration of culture, remains difficult. This apparent stage-specific reliance on the surrounding ovarian tissue, and inability to be cultured in vitro, is a clear indication that the ovarian environment may be required for culture of the smallest follicles in the 3D alginate system.

The influence and importance of the ovarian environment was elucidated in many new ways through the use 
of the alginate in vitro follicle culture system, which demonstrated that both physical mechanics and molecular support of the ovary can have an effect on follicle development. It has been shown that, while survival is not impacted, follicle growth and antrum formation are affected by the physical rigidity of the in vitro environment (Xu et al. 2006a). Additionally, follicles cultured in a more rigid environment have smaller oocytes, decreased steroid hormone production, a lower maturation rate, lower fertilization rate, and lower blastocyst formation rate than follicles cultured in a less rigid matrix (Xu et al. 2006a, West et al. 2007, West-Farrell et al. 2009). These data led to the hypothesis that the permissive/non-permissive conditions of culture mimic the natural environment within the ovary (West et al. 2007) to contribute to the function of the individual follicles. Our group has also found that molecular components of the ovarian stroma, particularly extracellular matrix (ECM), can affect follicle growth. While alginate alone cannot support small secondary follicle growth, alginate that has been modified to include collagen matrix or RGD peptides (that serve as a scaffold for integrin binding) can support some growth of the follicle, even in absence of FSH (Kreeger et al. 2006). This effect could be due to an impact on cell survival or proliferation, steroidogenesis, cell signaling, or cell differentiation, all of which may be affected by ECM (Woodruff \& Shea 2007). Our culture system is particularly useful in the growth and maturation of larger follicles, but the current alginate-only composition of the 3D matrix cannot support the growth of smaller follicles. It seems possible that a culture system that more closely resembles the native environment of the follicle could be a promising way to initiate and sustain the early growth of primordial, primary, and small secondary follicles.

Because there is clearly a stage-specific reliance on the physical mechanics and molecular support of the ovarian environment, it may be hypothesized that cells of the ovarian stroma themselves are instrumental in follicle development, particularly early follicle development that cannot be recapitulated by our current in vitro conditions. The ovarian stroma is a diverse mix of cell types and adhesion molecules that includes thecainterstitial cells, immune cells, endothelial cells of the blood vessels, smooth muscle cells, and several types of extracellular matrix proteins (Kent \& Ryle 1975, Paranko \& Pelliniemi 1992, Brannstrom et al. 1993, Best et al. 1996, Magoffin 2002, Berkholtz et al. 2006). Both thecainterstitial cells and immune cells are present in large numbers in the stroma, and both are known to be highly secretory cells (Nathan 1987, Brannstrom et al. 1993, Best et al. 1996, Magoffin 2002); we hypothesize that these cells could be key modulators of folliculogenesis. Of the ovarian immune cells, macrophages are present in the greatest numbers in the rat and human (Brannstrom et al. 1993, Best et al. 1996).
In this study, we investigated what effect a co-culture of ovarian stroma cells may have on in vitro growth of immature follicles. We find a significant increase in growth and survival of primary and early secondary follicles in the presence of an ovarian stromal population that consists mainly of thecal-interstitial cells and macrophages. We identify several factors produced by these stromal cells that may influence this growth and survival, and demonstrate that the co-culture recapitulates the in vivo ovarian environment in a way that is missing from previous culture systems. The work further accentuates the importance of the ovarian environment for culture of small follicles and provides the basis for improved culture outcome for these follicles.

\section{Results}

\section{Co-culture of pre-pubertal follicles with stromal cells}

Isolated small growing follicles (90-120 $\mu \mathrm{m})$ from day 16 animals were co-cultured with a feeder layer of ovarian stromal cells isolated from days 22 to 26 animals.

\section{Culture of early secondary follicles with stromal cells}

In the 3D culture system used, small secondary follicles (starting size of $\sim 120 \mu \mathrm{m}$ ) from the CD1 mouse strain do not grow in the absence of stromal cells or FSH (Fig. 1A). In fact, after 6 days in culture in the absence of $\mathrm{FSH}$, the follicles cultured without stromal cells begin to die at a high rate, and only about $30 \%$ survive to day 10 of culture; even those that survive do not grow (Fig. 1A and $\mathrm{B})$. However, when these follicles are cultured in the presence of stromal cells, they increase in size from $120 \mu \mathrm{m}$ in diameter to $\sim 190 \mu \mathrm{m}$ in diameter by day 10 and $75 \%$ of follicles survive the entire culture period (Fig. 1A and B). This phenomenon of superior growth and survival in the presence of stromal cells is further exaggerated when FSH is added to the culture media. While control follicles grown with $10 \mathrm{mIU} / \mathrm{ml} \mathrm{FSH}$ still do not grow significantly by day 10 of culture and have a low survival rate $(\sim 40 \%)$, follicles grown with stromal cells and $10 \mathrm{mIU} / \mathrm{ml}$ FSH reach over $270 \mu \mathrm{m}$ in diameter by day 10 and have a $98 \%$ survival rate (Fig. 1C and D).

\section{Culture of late primary and primary follicles with stromal cells}

Encouraged by the superior growth and survival of early secondary follicles, the experiments above were repeated for follicles with an average starting size of both $100 \mu \mathrm{m}$, which characterizes the late primary stage (Lenie et al. 2004), and $90 \mu \mathrm{m}$. Because FSH was found to be necessary for optimum growth, $10 \mathrm{mIU} / \mathrm{ml} \mathrm{FSH}$ was used for the duration of the culture in both 


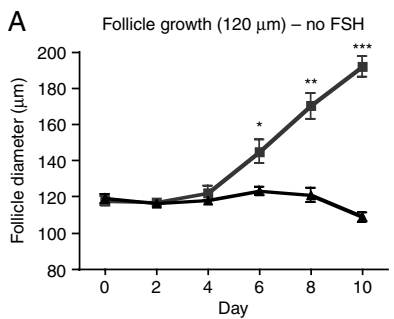

B
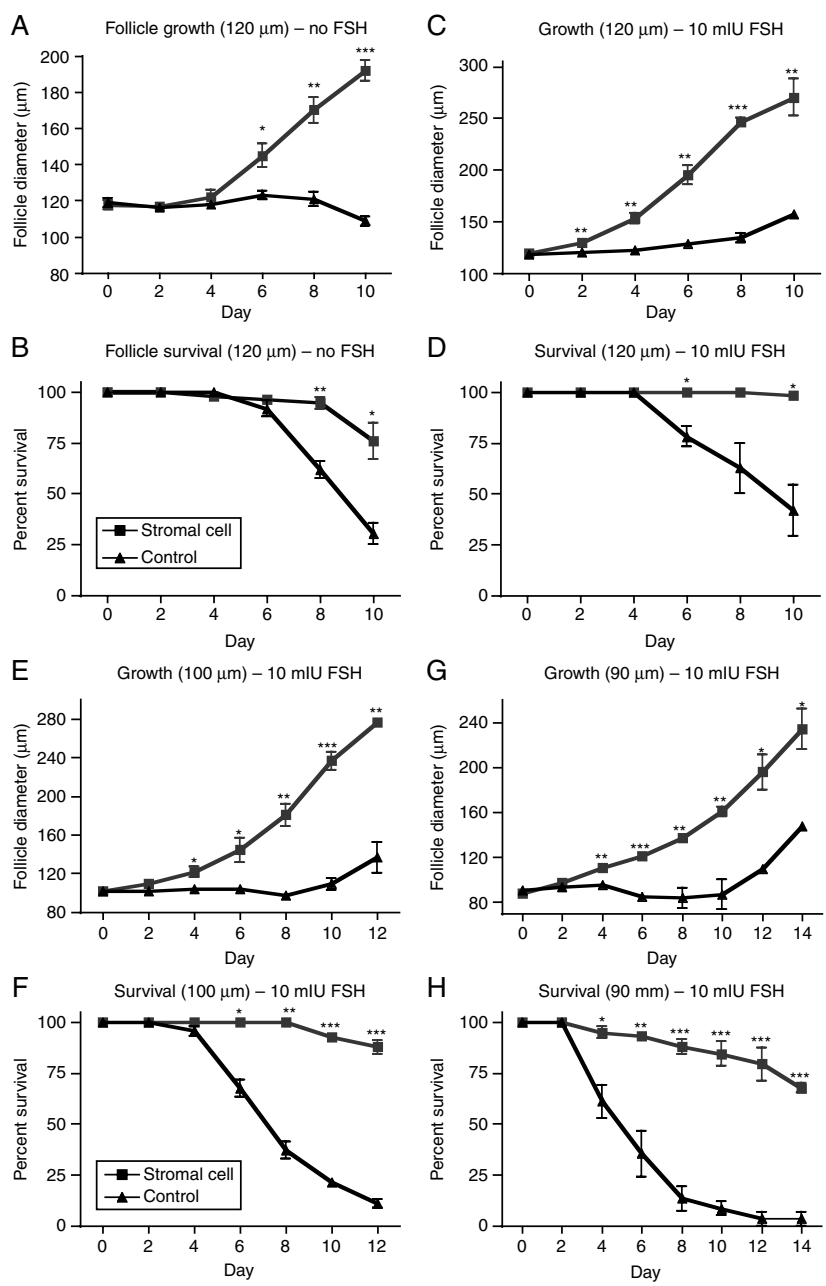

Figure 1 Co-culture experiments with stromal cells and follicles from pre-pubertal animals. Follicles of starting size of $120 \mu \mathrm{m}$ (small secondaries) were cultured either with no FSH in the media ( $\mathrm{A}$ and $\mathrm{B}$ ) or with $10 \mathrm{mlU} / \mathrm{ml} \mathrm{FSH}$ (C and D). Follicles with a starting size of $100 \mu \mathrm{m}$ ( $\mathrm{E}$ and $\mathrm{F}$ ) and $90 \mu \mathrm{m}(\mathrm{G}$ and $\mathrm{H}$ ) were cultured with $10 \mathrm{mIU} / \mathrm{ml} \mathrm{FSH}$ for the entire duration of culture. Follicle growth $(\mathrm{A}, \mathrm{C}, \mathrm{E}$, and $\mathrm{G})$ and survival $(B, D, F$, and $H)$ were measured. Black lines with triangle icons represent follicles cultured alone, while gray lines with square icons represent follicles cultured with an adherent layer of stromal cells. $N=60$ follicles for each group, 20 follicles in each group for triplicate experiments. ${ }^{*} P<0.05,{ }^{* *} P<0.01,{ }^{* * *} P<0.001$.

experiments. Late primary follicles cultured in this condition with stromal cells grow to over $275 \mu \mathrm{m}$ and have a survival rate of nearly $90 \%$ (Fig. 1E and F). The control follicles cultured without stromal cells in these conditions have only an $11 \%$ survival rate, and the few follicles that do survive grow to only about $135 \mu \mathrm{m}$ in diameter (Fig. 1E and F). For primary follicles of starting size of $90 \mu \mathrm{m}$, only 2 of 60 follicles cultured without stromal cells were still alive at the end of the 14-day culture period (3\% survival rate), while $\sim 70 \%$ of follicles cultured with stromal cells were alive and had grown to an average size of nearly $240 \mu \mathrm{m}$ (a 160\% increase in size; Fig. 1G and $\mathrm{H}$ ).

\section{Physiological mimicry of FSH levels in late primary/stromal cell co-culture}

In an attempt to recapitulate in vivo conditions seen by the follicles, late primary follicle culture conditions were created, wherein no FSH was added to media for the first 6 days of culture and $10 \mathrm{mIU} / \mathrm{ml} \mathrm{FSH}$ was added for all media changes from day 6 until the end of culture. The addition of $10 \mathrm{mIU} / \mathrm{ml} \mathrm{FSH}$ only to replaced media allowed a gradual increase in $\mathrm{FSH}$ level, as might be experienced by small growing follicles in the ovary (these follicles saw a concentration of $8.75 \mathrm{mIU} / \mathrm{ml} \mathrm{FSH}$ by day 12 of culture). As with all follicles described thus far, late primary follicles cultured in this condition in the absence of stromal cells did not grow (Fig. 2A). Additionally, only about $40 \%$ of these follicles survived until day 12 of culture (Fig. 2B). In contrast, late primary follicles cultured with stromal cells grew to an average size of nearly $175 \mu \mathrm{m}$ by day 12 , a $175 \%$ increase in size, and over $70 \%$ of follicles survived throughout culture (Fig. 2A and B). A second set of culture conditions also recapitulated a low FSH/high FSH environment by having $5 \mathrm{mIU} / \mathrm{ml} \mathrm{FSH}$ added to media for the first 6 days of culture and then $10 \mathrm{mIU} / \mathrm{ml}$ FSH added for all media changes from day 6 until the end of culture (FSH concentration in the media was $9.375 \mathrm{mIU} / \mathrm{ml}$ by day 12 of culture). The late primary follicles cultured in these conditions had a significant increase in growth and survival compared with follicles cultured without stromal cells. Follicle co-cultured with stromal cells grew to an average size of $\sim 270 \mu \mathrm{m}$ and had an incredible $93 \%$ survival rate, as compared to controls, which never grew and had only a $15 \%$ survival rate (Fig. 2C and D). Lower survival of control follicles in cultures with FSH added early, compared with FSH absent early, could be due to increased demands for, or attempts at, growth that are unsupported by the stromal cell influence (i.e. response to cues for growth rather than simply survival or maintenance). Examples of control or stromal cells co-cultured follicles grown from a starting size of $100 \mu \mathrm{m}$ in low FSH/high FSH conditions are shown in Fig. $2 \mathrm{E}$ and $\mathrm{F}$ respectively. By day 12 of culture, the control follicle has clearly begun to die, as the surrounding granulosa cells have lost contact with the oocyte in one hemisphere, and the oocyte has begun to be extruded from the follicle (Fig. 2E). In contrast, the follicle co-cultured with stromal cells has a visible antrum (asterisks) and the oocyte is asymmetrically located with surrounding somatic cells (arrow head, Fig. 2F).

\section{Characterization of stromal cells}

At the beginning of culture, stromal cells appeared morphologically heterogeneous. Nearly all cells at days 0,2 , and 4 of culture were flat and spread out on the culture dish. Many of these cells had apparent lipid 


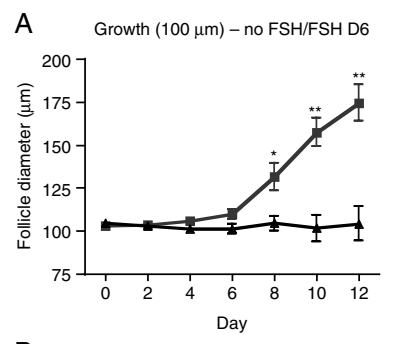

B Survival $(100 \mu \mathrm{m})-$ no FSH/FSH D6

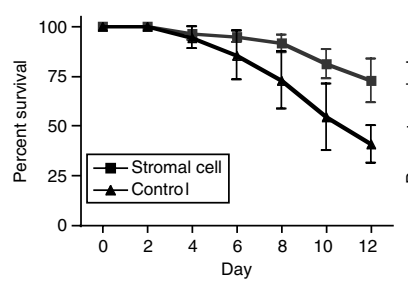

$\mathrm{FSH}$ :

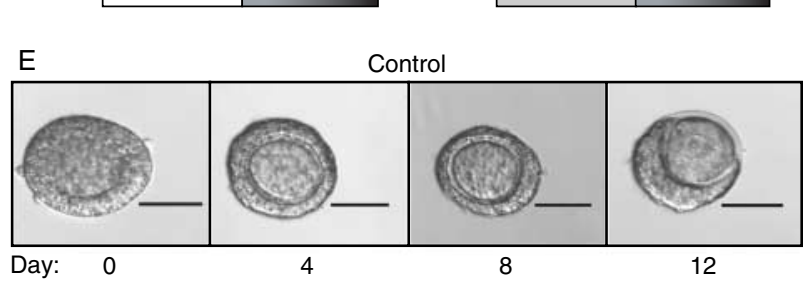

$\mathrm{F}$

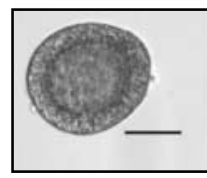

Day: 0

Figure 2 Physiological relevancy of FSH levels in co-culture experiments. Follicles of starting size $100 \mu \mathrm{m}$ (late primaries) were grown with no FSH for the first 6 days of culture and $10 \mathrm{mIU}$ FSH added to replaced media for days 6-12 of culture (A and B) or $5 \mathrm{mIU} \mathrm{FSH} \mathrm{for}$ the first 6 days of culture and $10 \mathrm{mIU} / \mathrm{ml} \mathrm{FSH}$ added to replaced media for days 6-12 of culture (C and D). Follicle growth (A and C) and survival (B and D) were measured (black lines with triangle icons represent follicles cultured alone, while gray lines with square icons represent follicles cultured with an adherent layer of stromal cells). $* P<0.05, * * P<0.01, * * * P<0.001$. Representative morphology of control (E) and stromal cell co-cultured (F) follicles cultured from a starting size of $100 \mu \mathrm{m}$ in low FSH/high FSH conditions are presented (the cumulus-oocyte complex (arrowhead) and antral cavities (asterisks) are indicated). Scale $=50 \mu \mathrm{m} . N=60$ follicles for each group, 20 follicles in each group for triplicate experiments.

droplets surrounding the nucleus that resembled thecal cells in morphology (Fig. 3A), though some cells lacked the nucleus-adjacent lipid droplets and appeared similar to fibroblasts. Indeed, alkaline phosphatase staining, used as a marker for theca cells, revealed that over $80 \%$ of cells were theca-like at day 0 of culture (Fig. 3D). The heterogeneity of the cellular morphology increased over the culture period, as rounded cells with long cytoplasmic processes were seen frequently by day 6 of culture (Fig. 3B). Because these cells resembled peritoneal macrophages in culture (Fig. 3C), we examined the expression of CD11b using ICC and adherent cytometer counts. Counts revealed that $\sim 18 \%$ of cells are macrophages at day $4, \sim 37 \%$ are macrophages by day 8 , and the majority of cells $(83 \%)$ are macrophages by day 12 (Fig. 3E). At the same time, the number of alkaline phosphatase-positive cells decreases significantly over the culture period, so that by days 8 and 12 of culture, the stromal cell feeder layer consists of $<15 \%$ AP-positive theca cells (data not shown). Therefore, the stromal cell population transitions from being mostly constituted by theca cells at day 0 of culture to being mostly ovarian macrophages by day 12 of culture.

\section{Macrophage number and localization during the pre-pubertal period}

Because the stromal cell population contained a large number of macrophages by the end of culture, the in vivo localization of ovarian macrophages in the pre-pubertal ovary was investigated to determine if culture conditions were physiologically relevant. No quantitative analysis of macrophage localization has ever been performed in the pre-pubertal ovary. To accomplish this, immunohistochemistry $(\mathrm{IHC})$ for the presence of macrophages was performed on ovaries from day postnatal $6,10,19$, and 26 mice. Ovaries were sectioned and stained for $\mathrm{f} 4 / 80$, a specific antibody used to identify macrophages and their immediate precursors (monocytes), which gives clear staining in paraffin-embedded sections (Austyn \& Gordon 1981). Concomitant follicle counts were performed with the macrophage cell counts.

We find that macrophages are associated with a heterogeneous population of follicles at every time point

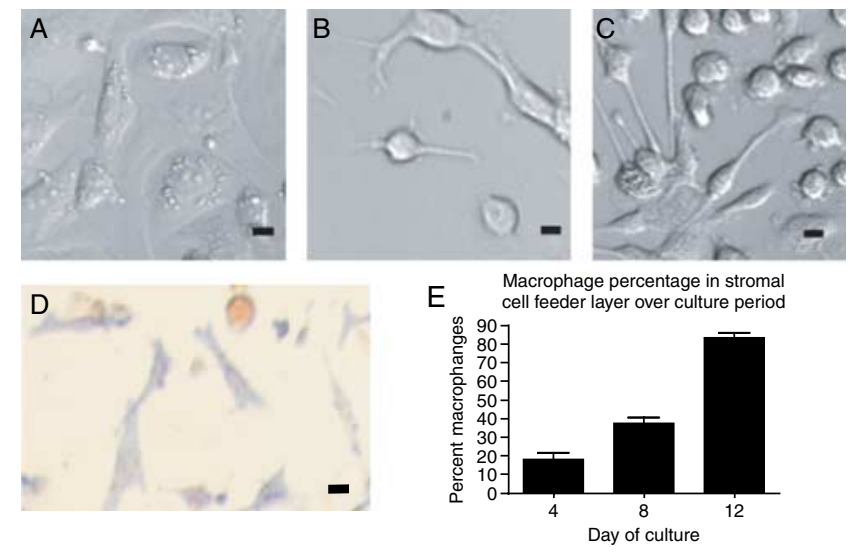

Figure 3 Morphological and molecular identification of the stromal cell population. (A) At day 2 of culture, most cells resemble theca cells morphologically, (B) but by day 6 of culture, new spherical cells with long cytoplasmic extensions become recognizable. The cells resemble (C) peritoneal macrophages in culture. (D) Alkaline phosphatase staining, a marker for theca cells, and (E) cell counts of positive CD11b staining, a marker for macrophages, are presented. Scale $=2 \mu \mathrm{m}$. 
examined. They are found with only a portion of each follicle class at every stage, with only atretic follicles always being associated with macrophages (Fig. 4 and Supplementary Figure 1, see section on supplementary data given at the end of this article). At day 6 , there is a significant association of macrophages with primordial and primary follicles (Supplementary Figure 1A). By day 10 , there is no longer a significant association of macrophages with primordial/primary follicles (Supplementary Figure 1B). Instead, days 10 and 19 counts show a strong association with healthy secondary and antral follicles (Supplementary Figure 1B and C). Primordial and primary follicles at day 26 show an interesting re-association with macrophages (Fig. 4A and B); day 26 also, like day 19, shows a strong association with atretic follicles (Supplementary Figure 1D). In summary, macrophages seem to show a strong association with primordial/primary follicles on day 6 (Fig. 4A and B), which changes to a more significant association with secondary/antral follicles on days 10 and 19 (Fig. 4C and D), and are-association with primordial/primary follicles
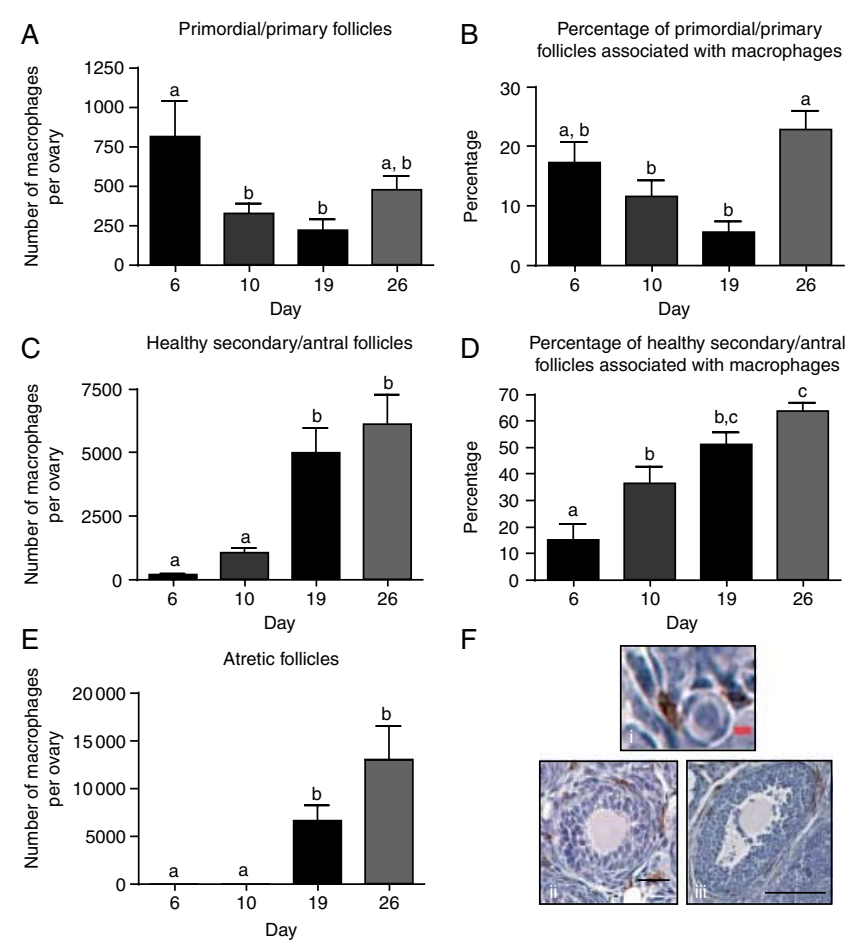

$\mathrm{F}$

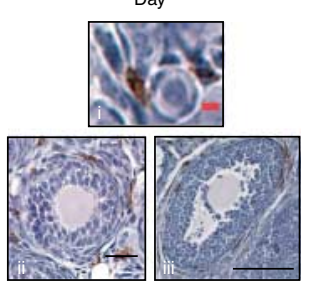

Figure 4 Quantitative analysis of ovarian macrophage localization and association with follicles across the pre-pubertal period. (A) The number of macrophages that were within one cell layer of a primordial or primary follicle was counted and (B) the percentage of these follicles that were associated with macrophages was counted concomitantly. The same macrophage $(C)$ and follicle (D) counts were performed for healthy secondary and antral follicles and (E) atretic follicles. (F) Representative histological images of association between macrophages and (i) primordial/primary follicles, (ii) healthy secondary/antral follicles, or (iii) atretic follicles are shown. Scale: black bar is $100 \mu \mathrm{m}$, red bar is $5 \mu \mathrm{m} . N$ (animals) $=7$ for day 6,9 for day 10,6 for day 19 , and 6 for day 26. Groups with different letters are significantly different. on day 26 (Fig. 4A and B). Macrophages are also always seen with atretic follicles when such follicles are present (Fig. 4E). Additionally, the number of macrophages associated per follicle is drastically increased depending on follicle class and day of examination. For example, each secondary and antral follicle associated with macrophages on day 19 is associated with an average of 204 macrophages, while each primordial or primary follicle is associated with an average of only six macrophages (Supplementary Table 1B and C, see section on supplementary data given at the end of this article). Representative histological images depicting macrophage association with primordial/primary follicles, healthy secondary/antral follicles, and atretic follicles are shown in Fig. 4Fi-Fiii. Macrophage localization profiles by day, macrophage association as a percentage of total, numbers in the stroma, and total numbers of ovarian macrophages by day are all represented in Supplementary Figures 1 and 2 (see section on supplementary data given at the end of this article) respectively.

\section{Secretion of cytokines and hormones in stromal cell-follicle co-culture}

The co-culture of stromal cells with follicles resulted in increased follicle growth and survival for primary, late primary, and small secondary follicles, in the absence or presence of FSH. Because the culture system used encapsulates follicles within a surrounding 3D alginate bead, no follicle cells are ever in direct contact with the adherent stromal cells cultured on the bottom of the well. Any effects exerted by the stromal cells must therefore be due to a secreted factor, either produced by, or in response to, the stromal cells. Because theca cells and macrophages are the major constituents of the stromal cell population, the culture media were analyzed for presence of cytokines and androgens. The media from day 2 of culture (either with or without FSH) was tested for the presence of 40 different secreted cytokines. In media from cultures with no FSH, many cytokines were upregulated when follicles were co-cultured with stromal cells, including IL6, KC, M-CSF, JE, MIP- $1 \alpha$, and MIP-2, though only M-CSF, MIP-1 $\alpha$, and TIMP1 reached statistical significance (Fig. 5A). Interestingly, several cytokines such as IL1 $\alpha$ and IL1 $\beta$ were significantly downregulated in stromal cell/follicle co-cultures versus follicles cultured by themselves. The pattern of regulation in the $5 \mathrm{mlU} / \mathrm{ml}$ FSH culture media was similar to that of the culture with no FSH in that IL6, KC, M-CSF, JE, MIP- $1 \alpha$, and MIP-2 were still upregulated (though only IP-10, JE, TNF, and TREM1 reached statistical significance), and IL1 $\alpha$ and IL1 $\beta$ were still significantly downregulated when follicles were co-cultured with stromal cells (Fig. 5B). That said, the degree of upregulation was significantly higher in the culture with FSH than that without. 

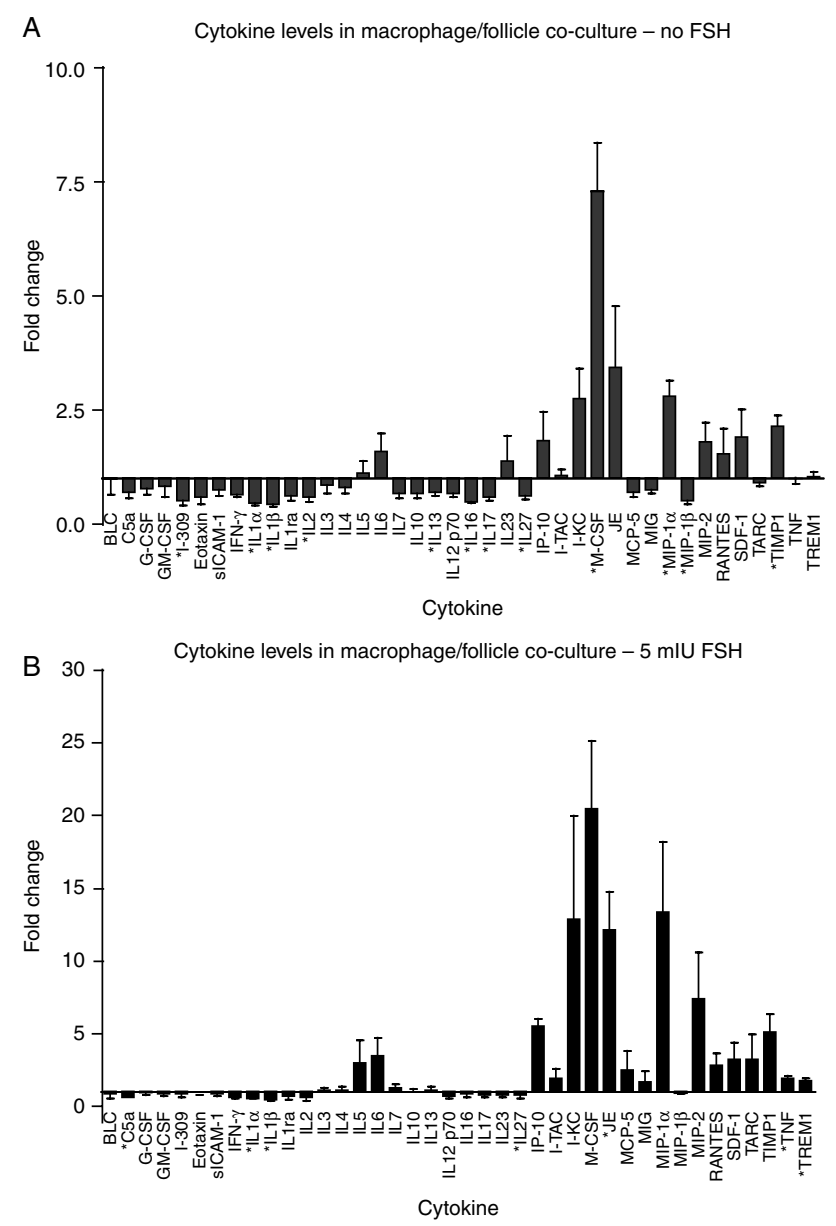

Figure 5 Assay of secreted cytokines on stromal cell/follicle co-culture. Media from day 2 of stromal cell/follicle co-culture in which no FSH (A) or 5 mIU FSH (B) was added to culture media was assayed for a variety of cytokines. Cytokine secretion is represented as the ratio of cytokine in stromal cell/follicle co-culture to that in follicles cultured alone (in the absence of stromal cells). $N=3$ for both experiments.

For example, the most upregulated cytokine in both trials was M-CSF: in the culture with no FSH, macrophage co-culture increased M-CSF 7.5-fold over control, while in the culture with FSH, M-CSF was increased an average of 20-fold when stromal cells were co-cultured with follicles. These data suggest several candidate cytokines and growth factors that may influence follicle growth and survival that are produced either by the stromal cells themselves or by the follicles in response to the presence of the stromal cells. Assaying for androstenedione showed that this androgen is produced by the stromal cells alone across the entire culture period (data not shown). At day 2 of culture, androstenedione levels are $<1 \mathrm{ng} / \mathrm{ml}$; this level increases to $\sim 4 \mathrm{ng} / \mathrm{ml}$ by day 4 of culture, and is $>10 \mathrm{ng} / \mathrm{ml}$ on every subsequent day of culture. The level of androstenedione produced by the stromal cells is not significantly changed in the presence or absence of follicles (data not shown).

\section{Effect of androstenedione and cytokines on follicle development}

Several of the cytokines, as well as androgen, that were found to be differentially produced in stromal cell/follicle co-culture were added to follicle culture in the absence of any co-culturing. Follicles of $100 \mu \mathrm{m}$ starting size were cultured with $10 \mathrm{mIU} / \mathrm{ml} \mathrm{FSH}$ and either 1) $0.1,1,10,50$, or $100 \mathrm{ng} / \mathrm{ml} \mathrm{M}$-CSF, 2) combinations of $50 / 0.05,300 / 0.1,500 / 1 \mathrm{ng} / \mathrm{ml}$ of IP-10/IL6, 3) combinations of 10,50 , or $100 \mathrm{ng} / \mathrm{ml}$ each of MIP- $1 \alpha$, JE, KC, and M-CSF, or 4) increasing levels of androstenedione $(1 \mathrm{ng} / \mathrm{ml}$ on day $0,4 \mathrm{ng} / \mathrm{ml}$ on days 2 , and $10 \mathrm{ng} / \mathrm{ml}$ on day 4-end of culture). None of these isolated or combined cytokines or androgens were able to recapitulate the improved growth and survival of small follicles, as seen with stromal cell co-culture, suggesting that the milieu created by these cells is more complex than these few chosen components.

\section{Discussion}

We have found that both small secondary and late primary follicles isolated from the pre-pubertal ovary have increased follicle growth, granulosa cell proliferation, and follicle survival when cultured in the presence of ovarian stromal cells. This is the first study, to our knowledge, to examine direct co-culture of pre-pubertal stromal cells and isolated follicles in vitro, as is made possible by the 3D alginate culture system. We have demonstrated that small follicles have a stagespecific reliance on stromal cell co-culture, that our co-culture system recapitulates in vivo conditions through the presence of theca cells and the physiologically relevant association of macrophages, and that the stromal cells present produce androgens and cytokines that may be important for the growth and survival effects observed.

\section{Macrophages are associated with growing follicles in the pre-pubertal ovary}

We find that the stromal cell population is predominantly made up of macrophages by the end of culture. In order to determine whether the association of these immune cells with growing follicles is physiologically relevant, we examined the localization of macrophages with each follicle class across the prepubertal period.

Our study clearly demonstrates that macrophages are associated with healthy growing follicles in the prepubertal ovary, in addition to the association with dying follicles that may be expected. The presence of macrophages in the pre-pubertal ovary is not surprising, as macrophages have been observed in the adult ovary of the mouse, pig, rat, and human (Bulmer 1964, Gillim et al. 1969, Paavola 1979, Hume et al. 1984, 
Brannstrom et al. 1993, 1995b, Simon et al. 1994, Best et al. 1996, Petrovska et al. 1996, Katabuchi et al. 1997, Takaya et al. 1997, Gaytan et al. 1998, Li et al. 1998). In light of our examination of macrophages in the prepubertal ovary, we propose a model by which to explain the macrophage localization data observed. There is a significant association of macrophages with the smallest class of follicle when this cohort begins to grow around day 6 (Fig. 6, Box A). As these follicles continue to grow, the macrophages remain associated with them, therefore showing a higher association with larger follicles on days 10 and 19 (Fig. 6, Box B). At the same time, macrophages are attracted to atretic follicles (Fig. 6, Box B). As the first pre-ovulatory class of follicles prepares to ovulate (around day 28), the ovary must begin recruiting the next cohort of pre-ovulatory follicles. A reassociation of macrophages with small follicles is therefore seen around day 26 (Fig. 6, Box C). It is expected that the pattern of macrophage association seen earlier will be cyclical so that by day 30, macrophages would again be more significantly associated with secondary follicles (Fig. 6, Box D).

Though no study has performed quantitative analysis of macrophage number concomitant with follicle counts in the pre-pubertal ovary, our results, and our model proposed, are supported by macrophage counts in the adult ovary and qualitative analysis in the pre-pubertal ovary. In studies of the adult ovary in which the association of macrophages with certain classes of follicle has been followed, there is a correlation between macrophage association and follicle maturity in both the mouse and the human (Petrovska et al. 1996, Katabuchi et al. 1997). These data confirm the physiological relevancy of our culture system, which has an increasing number of macrophages as the follicle grows. In contrast to our data in the pre-pubertal ovary, the studies in the

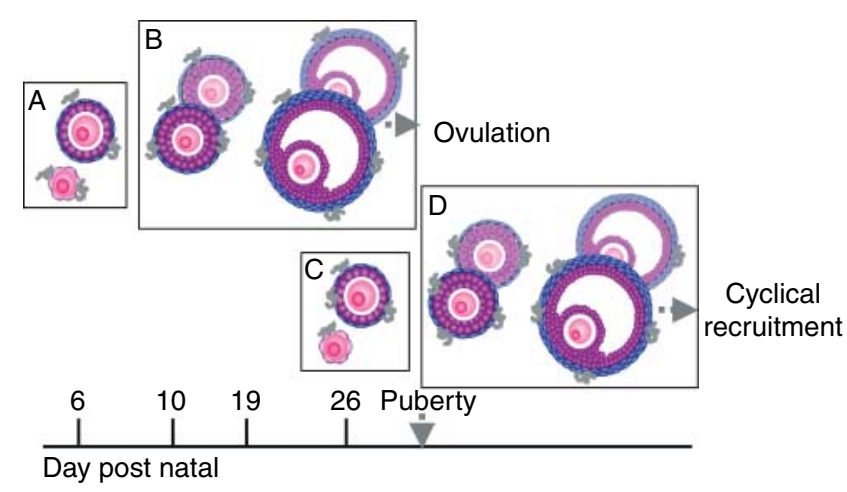

Figure 6 Model of macrophage association with follicles during the prepubertal period. The model proposed states an initial association of macrophages with primordial and primary follicles (A) that changes to an association with secondary and antral follicles as the initial follicles grow (B) and some of them undergo atresia. Later, a new cohort of primordial and primary follicles become associated with macrophages (C) and the cycle repeats itself with larger follicles (D). adult ovary of both humans and mice show no macrophages associated with primordial and primary follicles (Petrovska et al. 1996, Katabuchi et al. 1997, Takaya et al. 1997). This discrepancy is likely due to the absence of any scoring system for qualitatively or quantitatively assessing macrophage number (Katabuchi et al. 1997) or the practice of only counting macrophages that are within a follicle (Petrovska et al. 1996). A single study quantitatively accessing follicle association with macrophages (but not macrophage number) in the pre-pubertal mouse ovary did no counts of primordial or primary follicles, but do corroborate our data in finding an association of macrophages with healthy growing follicles, in addition to atretic ones (Gaytan et al. 1998). Lastly, though the study is very qualitative and performs no actual counts of macrophages or follicles, our data are nicely corroborated by a second study of pre-pubertal ovarian macrophages, which states that macrophages are seen among primary follicles on day 7 , in the theca of growing follicles on day 14 , and heavily populating the interstitium by day 21 (Li et al. 1998).

Our demonstration of macrophage association with healthy, growing follicles indicates that phagocytosis of dead cells may not be the only, or even the main role of macrophages in the ovary. This idea is supported by data that shows that ovarian macrophages are more weakly phagocytic than peritoneal or testicular macrophages (Itoh et al. 1999), and that ovarian macrophages surrounding developing non-atretic follicles in the adult ovary do not contain vacuoles or granules present in the cytoplasm that would indicate phagocytic activity (Katabuchi et al. 1997). Because macrophages secrete over 100 cytokines, growth factors, ECM components, and bioactive lipids and peptide products that can act locally (Nathan 1987), our method of counting macrophages that are not only within a follicle, but also closely associated with it (within one cell layer of the outer layer of the follicle), provides a much clearer understanding of the contribution of both secretory and phagocytic (two activities that are not always mutually inclusive (Butler et al. 1982)) macrophages to follicle development.

\section{Influence of theca cells on early follicle development}

In contrast to the ovarian macrophages that predominate in the stromal cell feeder layer later in culture, theca cells predominate in the beginning of culture. In culture, follicles that have a preserved theca cell layer grow much better than follicles with only a few theca cells when only LH is added to the media, demonstrating the importance of theca cells in in vitro cultures (Cortvrindt et al. 1998). It is possible that the stromal cell co-culture system developed provides theca cells that are normally associated with the follicle in vivo, but that become lost due to the follicle isolation procedure. Surprisingly, 
though theca cell number as percentage of total cells decreases over the culture period, androgen production continues to increase throughout culture. This apparent discrepancy is likely due to the proliferation of cells in the feeder layer over time that seems to favor macrophage proliferation, thereby giving a fairly stable number of theca cells over the culture duration. The theca cells that are present could also gain an increased steroidogenic ability over time; current studies are examining the theca cells in the feeder layer in more detail to investigate their full steroidogenic activity and interactions between the theca cells and other cells within the feeder layer.

\section{Production of cytokines and hormones in the stromal cell co-culture and their possible role in small follicle growth}

We find that several cytokines and growth factors are differentially regulated by the addition of stromal cells to follicle culture; these cytokines and growth factors are possible products of the macrophages present in the stromal cell population or products of the follicle produced in response to the presence of the macrophage-enriched stromal cells in culture. Indeed, previous observations have shown direct effects of macrophages and their secreted cytokines on follicular cells and the process of ovulation. In vitro, co-culturing macrophages with granulosa cells causes an increase in granulosa cell proliferation and an increase in progesterone production (Kirsch et al. 1983, Polan et al. 1989, Fukumatsu et al. 1992); this steroidogenic effect has also been seen in ovarian luteal cells co-cultured with macrophages (Halme et al. 1985). Peritoneal macrophages and ovarian macrophages both increase the progesterone production of granulosa and granulosaluteal cells when they are added to culture (Kirsch et al. 1981,1983, Halme et al. 1985). In addition, it has been shown that cytokine production by granulosa cells is increased by co-culture with macrophages and that granulosa cell-conditioned media causes migration of immune cells towards the source (Polec et al. 2009). Reproductive effects can be seen in models of macrophage depletion, further demonstrating a role of macrophages in ovarian processes. A model of specific ovarian macrophage depletion demonstrates a negative effect on the number of ovulations (Van der Hoek et al. 2000), while systemic loss of macrophages and the expression of CSF-1 lead to several reproductive effects, including fewer mature follicles and fewer ovulations (Araki et al. 1996, Cohen et al. 1997). Finally, many of the cytokines we found to be highly regulated by stromal cell co-culture and/or FSH, namely M-CSF, IL6, and JE/ MCP-1, have been previously shown to be regulated by $\mathrm{FSH}$ and highly purified urinary menotropin in isolated cultured mouse follicles (Foster et al. 2010).
In addition to the large array of cytokines and growth factors measured, we also measured high levels of androgens produced by the stromal cells, likely through the specific actions of the theca-like cells in the population. Androgens can be aromatized to estrogens by the mature granulosa cells (Short 1962, Liu \& Hsueh 1986); androgens have been shown to have a positive effect on follicle growth in mice, cows, and non-human primates (Murray et al. 1998, Vendola et al. 1998, Yang \& Fortune 2006). In bovines, cortical strips cultured in vitro contained a higher number of secondary follicles when cultured in the presence of testosterone, while primordial and primary follicle numbers were not significantly affected (Yang \& Fortune 2006). The mouse model demonstrates similar results: an androgen receptor antagonist or anti-androgen serum slows the growth of isolated in vitro cultured follicles, while culturing with dihydrotestosterone (DHT) increases the growth of large follicles (Murray et al. 1998). In the nonhuman primate, in vivo treatment with testosterone increased the number of healthy primary, secondary and small antral follicles. Granulosa and thecal cell proliferation were increased in these groups over controls, and follicle atresia and granulosa cell apoptosis were decreased (Vendola et al. 1998). Ovarian apoptosis was also suppressed by androgen in cultures of human ovarian tissue in vitro (Otala et al. 2004). This antiatretogenic effect of androgens is in conflict with data from hypophysectomized rats, which demonstrates that DHT treatment in vivo caused a large amount of follicle atresia in primary, secondary, and tertiary follicles (Bagnell et al. 1982, Billig et al. 1993). This discrepancy could be due to the particular model and the lack of endogenous gonadotropin control.

Despite these large differences in cytokine and androgen production, neither several cytokines (M-CSF, IP-10, IL6, MIP-1 $\alpha, \mathrm{KC}$ and JE) nor androgen (androstenedione) could fully recapitulate the improved growth and survival of primary and early secondary follicles seen with ovarian stromal cell co-culture. This suggests that the co-culture system developed provides a complex milieu of hormones and cytokines, as well as possible inhibitors and growth factors, which is ideally suited for optimal growth of small follicles. It is also possible that the cytokines and other factors produced in the stromal cell/follicle co-culture are the result of the interaction between the feeder layer and the follicle itself, and that a feedback loop exists where both must be present for the optimal degree of factor regulation required for increased follicle growth and survival.

In conclusion, we have developed a stromal cell co-culture system for follicles that recapitulates the in vivo environment of the ovary by providing theca and macrophage cell influence. This stromal cell support is required in a stage-specific manner for the growth and survival of small follicles. Further work in characterizing 
the molecular and biochemical support provided by each constituent of the stromal cell population will optimize the system and even further expand our ability to successfully mature small follicles in vitro.

\section{Materials and Methods}

\section{Animals}

CD1 mice were maintained in accordance with the policies of the Northwestern University's Animal Care and Use Committee. Mice were housed and bred in a controlled barrier facility within Northwestern University's Center for Comparative Medicine (Chicago, IL, USA) and were provided with food and water ad libitum. Temperature, humidity, and photoperiod (14 h light:10 h darkness) were kept constant. Animals were fed Teklad Global (Madison, WI, USA) irradiated 2919 or 2916 chow, which does not contain soybean or alfalfa meal and contains minimal phytoestrogens.

\section{Tissue processing and histological staining}

Mouse ovaries (from days 6, 10, 19, and 26 animals) were placed in $4 \%$ formaldehyde (Sigma) fixative for $8-24 \mathrm{~h}$, depending on size. The tissue was then dehydrated and paraffin embedded. Sections $(5 \mu \mathrm{m})$ were cut with a microtome and mounted on Superfrost-Plus slides (Vector Laboratories, Inc., Burlingame, CA, USA) or Surgipath Snowcoat Extra slides (Surgipath, Richmond, IL, USA). Hematoxylin and eosin staining were performed using a Leica Autostainer XL (Leica Microsystems, Wetzlar, Germany). All tissue processing was performed by the Northwestern University Center for Reproductive Sciences Histology Core.

\section{Antibodies}

The antigen $\mathrm{f} 4 / 80$ was detected by IHC using the rat monoclonal anti-f4/80 (Clone C1:A3-1, Cat. \#ab6640, Abcam, Inc., Cambridge, MA, USA) at a primary antibody concentration of 1:50. The antigen CD11b was detected by immunocytochemistry (ICC), using the FITC-conjugated rat monoclonal anti-mouse CD11b (recognizes the $170 \mathrm{kDa} \alpha[\mathrm{M}]$ chain of CD11b, Cat. \#553310, BD Biosciences, San Jose, CA, USA) at a concentration of $0.5 \mu \mathrm{g} / \mathrm{ml}$.

\section{Immunohistochemistry}

IHC for f4/80 was performed as previously described (BristolGould et al. 2006a), except that no antigen retrieval was performed. Adult mouse spleen tissue was used as a positive control, while protocol lacking primary antibody served as negative control. Staining of bursal macrophages was also determined to be an internal positive control at all time points.

\section{ICC and cell counting}

ICC for CD11b was performed as follows: live adhered ovarian stroma cells at day 4,8 , or 12 of cell culture were washed three times with $100 \mu \mathrm{l}$ staining buffer $(1 \times$ PBS with $2 \%$ FCS and $0.1 \%$ sodium azide), then incubated in the dark for 30 min with $0.5 \mu \mathrm{g} / \mathrm{ml}$ FITC- $\alpha$-CD11 b and $5 \mu \mathrm{g} / \mathrm{ml}$ Hoechst 3342 prepared in staining buffer. Following incubation, cells were washed three times with $100 \mu$ l staining buffer and then imaged within $1 \mathrm{~h}$. Imaging and cell counts were performed using the Cyntellect Celigo Adherent Flow Cytometer with two-channel detection (Hoechst- Excitation: 377, Emission: 447 and FITCExcitation: 483, Emission: 536) (Cyntellect, Inc., San Diego, CA, USA). Analysis was performed using a modified live/dead protocol with intensity gating of 2 and size gating of 10 or 15 for Hoechst and FITC channels respectively.

\section{Alkaline phosphatase staining}

Alkaline phosphatase (AP) staining was performed as previously described (Cortvrindt et al. 1998). Briefly, adherent cultured stromal cells were washed three times with PBS, fixed for $5 \mathrm{~min}$ with $4 \%$ paraformaldehyde, and washed three more times with PBS. Cells were then incubated in the dark in histochemical stain solution $(0.25 \mathrm{mg} / \mathrm{ml}$ naphtol $\mathrm{AS} / \mathrm{BI}$ phosphate and $0.75 \mathrm{mg} / \mathrm{ml}$ fast blue salt prepared in $0.2 \mathrm{M}$ Tris- $\mathrm{HCl}, \mathrm{pH}$ 9.3) for $45 \mathrm{~min}$. Following incubation, cells were washed three times with double-deionized water $\left(\mathrm{ddH}_{2} \mathrm{O}\right)$ and counterstained with $0.5 \%$ nuclear Fast Red for $10 \mathrm{~min}$. Following three washes with $\mathrm{dd}_{2} \mathrm{O}$, cells were imaged. Cell counts were performed in three random parts of each well ( $n=5$ wells for each day examined) and represented as percent AP positive out of total cells. If individual cells could not be examined due to a cell mass, a calculated estimate was made on percent positive for AP staining.

\section{Macrophage and follicle counting}

Macrophages were counted in every 10th section as being associated with primordial/primary follicles (follicles with only a single granulosa cell surrounding them), healthy secondary/ antral follicles (follicles with multiple granulosa cell layers with complete absence of pyknotic nuclei), atretic follicles (follicles characterized morphologically by the presence of at least one pyknotic nuclei), or stroma tissue. A macrophage was considered to be associated with a follicle if it was within one cell layer of the outermost portion of the follicle (the granulosa layer in monolaminar follicles and the outermost theca cell layer in larger follicles), and was considered to be in the stroma if it was not in the immediate vicinity of any follicles. A macrophage that was close to two follicles of different classes was counted in the numbers of both classes, but only counted once in the total. Because macrophages have long pseudopodia-like extensions that could traverse multiple sections, double counting of cells was avoided by counting only stained cells, where the nucleus, as stained by hematoxylin counterstaining, could be detected. Macrophage nuclei were small enough not to be double counted in multiple sections, so the average number of cells per section was multiplied by the total number of sections obtained to find the number of macrophages associated with each type of follicle class per ovary. Macrophage numbers are presented as per ovary counts, unless otherwise noted. Representative images of 
macrophage association with each class of follicle counted are shown in Fig. 4F and Supplementary Figure 3, see section on supplementary data given at the end of this article.

Follicle counts were also performed in the ovaries of prepubertal animals, as previously described (Bristol-Gould et al. 2006b, Tingen et al. 2009).

\section{Ovarian stromal cell isolation and plating}

Ovaries isolated from day 22 to day 26 animals with the bursa removed were placed in media containing L15, 0.5\% Pen-Strep and $1 \mathrm{mg} / \mathrm{ml}$ BSA ('wash media'). Two insulin gauge needles were used to poke each ovary 100 times to release granulosa cells. The remaining 'husk' was cut into eight pieces, placed into dissociation media (wash media with $0.1 \%$ collagenase and $0.01 \%$ DNAse I), and pipetted with a $1 \mathrm{ml}$ tip gently. Tissue was then incubated for $1 \mathrm{~h}$ at $37^{\circ} \mathrm{C}$ in a $95 \%$ air $/ 5 \% \mathrm{CO}_{2}$ chamber, pipetting every $15 \mathrm{~min}$ with successively smallerorificed pipette tips to break up the tissue. Tissue was placed back in incubator between pipettings. Solution was allowed to settle and supernatant was transferred to eppendorf tubes. Solution was then pelleted (1485 $\mathrm{g}$ for $5 \mathrm{~min}$ ) and washed once each with $37^{\circ} \mathrm{C}$ wash media and $37^{\circ} \mathrm{C}$ plating media (RPMI 1640 containing $25 \mathrm{mM}$ HEPES and $2 \mathrm{mM}$ L-glutamine (Cat. \#22400-071 Gibco Invitrogen) with 10\% heat-inactivated FCS (Cat. \# 10082-139 Gibco Invitrogen) and 1\% Pen-Strep). Cells were then resuspended in 1-2 $\mathrm{ml}$ plating media and plated in 96-well polystyrene plates at an approximate density of 150000 cells per well. Cells were incubated at $37^{\circ} \mathrm{C}$ for $3 \mathrm{~h}$ in a $95 \%$ air $/ 5 \% \mathrm{CO}_{2}$ chamber, and then all non-adhered cells were removed by washing plates three times with $37^{\circ} \mathrm{C}$ PBS. Cells were then allowed to 'rest' in plating media at $37^{\circ} \mathrm{C}$ in a $95 \%$ air $/ 5 \% \mathrm{CO}_{2}$ chamber overnight. All wells were washed three times with $37^{\circ} \mathrm{C}$ PBS the following day before follicles and follicle growth media (as described in 'follicle isolation, encapsulation, culture, and diameter measurement') were added in order to remove all of the plating media containing serum.

\section{Follicle isolation, encapsulation, culture, and diameter measurement}

Follicle isolation, encapsulation, culture, and measurement of follicle diameter were performed as previously described ( $\mathrm{Xu}$ et al. 2006a), with following modifications: alginate concentration used was $0.5 \%$ instead of $1.5 \%$ and ovaries were not incubated in $\alpha \mathrm{MEM} / \mathrm{FBS} / \mathrm{collagenase/DNAsel} \mathrm{prior} \mathrm{to} \mathrm{mechan-}$ ical isolation. Starting sizes of follicles were also either $\sim 90$, 100-105, or $120 \mu \mathrm{m}$, as described for each experiment in 'Results', FSH was added as described in 'Results', and cultures were of a 10- or 12-day duration. Follicles were isolated from day 16 animals and all culture experiments had 20 follicles in each follicle group, with each experiment performed in triplicate, for a total of 60 follicles per group. As previously described (Xu et al. 2006b), follicles were considered dead if the oocyte was no longer surrounded by a granulosa cell layer, if the granulosa cells had become dark and fragmented, and the follicle had decreased in size, or if the oocyte had fragmented.

\section{Cytokine and hormone analysis from conditioned media}

Media collected after media change (every other day during culture) was placed in 96-well plates and frozen at $-80^{\circ} \mathrm{C}$ until use. For each cytokine array, five wells worth of media were pooled ( $\sim 250 \mu \mathrm{l}$ total) and $240 \mu \mathrm{l}$ of media were used in the Proteome Profiler Mouse Cytokine Array/Panel A Array Kit (Cat. \#ARY006, R\&D Systems, Minneapolis, MN, USA), as instructed by the manufacturer, except that the streptavidinHRP was diluted at 1:200. For each hormone assay, five wells worth of media were pooled ( $\sim 250 \mu$ l total) and $25 \mu$ l of media were used for each condition in the Active Androstenedione Enzyme Immunoassay Kit (Cat. \#DSL-10-3800, Diagnostic Systems Laboratories, Webster, TX, USA), as instructed by the manufacturer.

\section{Statistical analysis}

Data were analyzed by one-way ANOVA between groups, followed by a Tukey test of significance for macrophage localization. For follicle sizes and survival, an unpaired, twotailed $t$-test was performed between macrophage and control groups at each day. A one-sample $t$-test was used to compare fold change of cytokine levels to a theoretical value of 1 . Significance was determined for $P<0.05$. All statistical analyses were performed using GraphPad Prism 4 (GraphPad Software, Inc., San Diego, CA, USA).

\section{Supplementary data}

This is linked to the online version of the paper at http://dx.doi. org/10.1530/REP-10-0483.

\section{Declaration of interest}

The authors declare that there is no conflict of interest that could be perceived as prejudicing the impartiality of the research reported.

\section{Funding}

This work is supported by NIH U54 HD041857, the Summer Research Fellowship award from the Endocrine Society, and the Marcia Storch award from the Center for Reproductive Science at Northwestern University to Cristina Thomas.

\section{Acknowledgements}

The authors thank Alison Kim for critical reading of the manuscript and figure preparation and Miranda Bernhardt for assistance in peritoneal macrophage isolation protocol.

\section{References}

Adriaens I, Cortvrindt R \& Smitz J 2004 Differential FSH exposure in preantral follicle culture has marked effects on folliculogenesis and oocyte developmental competence. Human Reproduction 19 398-408. (doi:10.1093/humrep/deh074) 
Araki M, Fukumatsu Y, Katabuchi H, Shultz LD, Takahashi K \& Okamura H 1996 Follicular development and ovulation in macrophage colonystimulating factor-deficient mice homozygous for the osteopetrosis (op) mutation. Biology of Reproduction 54 478-484. (doi:10.1095/biolreprod54.2.478)

Austyn JM \& Gordon S 1981 F4/80, a monoclonal antibody directed specifically against the mouse macrophage. European Journal of Immunology 11 805-815. (doi:10.1002/eji.1830111013)

Bagnell CA, Mills TM, Costoff A \& Mahesh VB 1982 A model for the study of androgen effects on follicular atresia and ovulation. Biology of Reproduction 27 903-914. (doi:10.1095/biolreprod27.4.903)

Berkholtz CB, Lai BE, Woodruff TK \& Shea LD 2006 Distribution of extracellular matrix proteins type I collagen, type IV collagen, fibronectin, and laminin in mouse folliculogenesis. Histochemistry and Cell Biology 126 583-592. (doi:10.1007/s00418-006-0194-1)

Best CL, Pudney J, Welch WR, Burger N \& Hill JA 1996 Localization and characterization of white blood cell populations within the human ovary throughout the menstrual cycle and menopause. Human Reproduction 11 790-797.

Billig H, Furuta I \& Hsueh AJ 1993 Estrogens inhibit and androgens enhance ovarian granulosa cell apoptosis. Endocrinology 133 2204-2212. (doi:10.1210/en.133.5.2204)

Brannstrom M, Mayrhofer G \& Robertson SA 1993 Localization of leukocyte subsets in the rat ovary during the periovulatory period. Biology of Reproduction 48 277-286. (doi:10.1095/biolreprod48.2.277)

Bristol-Gould SK, Kreeger PK, Selkirk CG, Kilen SM, Cook RW, Kipp JL, Shea LD, Mayo KE \& Woodruff TK 2006a Postnatal regulation of germ cells by activin: the establishment of the initial follicle pool. Developmental Biology 298 132-148. (doi:10.1016/j.ydbio.2006. 06.025)

Bristol-Gould SK, Kreeger PK, Selkirk CG, Kilen SM, Mayo KE, Shea LD \& Woodruff TK 2006b Fate of the initial follicle pool: empirical and mathematical evidence supporting its sufficiency for adult fertility. Developmental Biology 298 149-154. (doi:10.1016/j.ydbio.2006.06. 023)

Bukovsky A, Chen TT, Wimalasena J \& Caudle MR 1993 Cellular localization of luteinizing hormone receptor immunoreactivity in the ovaries of immature, gonadotropin-primed and normal cycling rats. Biology of Reproduction 48 1367-1382. (doi:10.1095/biolreprod48.6. 1367)

Bukovsky A, Caudle MR, Keenan JA, Wimalasena J, Upadhyaya NB \& Van Meter SE 1995a Is corpus luteum regression an immune-mediated event? Localization of immune system components and luteinizing hormone receptor in human corpora lutea Biology of Reproduction $\mathbf{5 3}$ 1373-1384. (doi:10.1095/biolreprod53.6.1373)

Bukovsky A, Keenan JA, Caudle MR, Wimalasena J, Upadhyaya NB \& Van Meter SE 1995b Immunohistochemical studies of the adult human ovary: possible contribution of immune and epithelial factors to folliculogenesis. American Journal of Reproductive Immunology 33 323-340.

Bulmer D 1964 The histochemistry of ovarian macrophages in the rat. Journal of Anatomy 98 313-319.

Butler T, Spagnuolo PJ, Goldsmith GH \& Aikawa M 1982 Interaction of Borrelia spirochetes with human mononuclear leukocytes causes production of leukocytic pyrogen and thromboplastin. Journal of Laboratory and Clinical Medicine 99 709-721.

Cohen PE, Zhu L \& Pollard JW 1997 Absence of colony stimulating factor-1 in osteopetrotic (csfmop/csfmop) mice disrupts estrous cycles and ovulation. Biology of Reproduction 56 110-118. (doi:10.1095/biolreprod56.1.110)

Cortvrindt R, Hu Y \& Smitz J 1998 Recombinant luteinizing hormone as a survival and differentiation factor increases oocyte maturation in recombinant follicle stimulating hormone-supplemented mouse preantral follicle culture. Human Reproduction 13 1292-1302. (doi:10. 1093/humrep/13.5.1292)

Foster R, Segers I, Smart D, Adriaenssens T, Smitz J, Arce JC \& Princivalle M 2010 A differential cytokine expression profile is induced by highly purified human menopausal gonadotropin and recombinant follicle-stimulating hormone in a pre- and postovulatory mouse follicle culture model. Fertility and Sterility 93 1464-1476. (doi:10.1016/ j.fertnstert.2009.01.136)
Fukumatsu Y, Katabuchi H, Naito M, Takeya M, Takahashi K \& Okamura H 1992 Effect of macrophages on proliferation of granulosa cells in the ovary in rats. Journal of Reproduction and Fertility 96 241-249. (doi:10. 1530/jr.0.0960241)

Gaytan F, Morales C, Bellido C, Aguilar E \& Sanchez-Criado JE 1998 Ovarian follicle macrophages: is follicular atresia in the immature rat a macrophage-mediated event? Biology of Reproduction 58 52-59. (doi:10.1095/biolreprod58.1.52)

Gillim SW, Christensen AK \& McLennan CE 1969 Fine structure of the human menstrual corpus luteum at its stage of maximum secretory activity. American Journal of Anatomy 126 409-427. (doi:10.1002/aja. 1001260403)

Halme J, Hammond MG, Syrop CH \& Talbert LM 1985 Peritoneal macrophages modulate human granulosa-luteal cell progesterone production. Journal of Clinical Endocrinology and Metabolism 61 912-916. (doi:10.1210/jcem-61-5-912)

Hume DA, Halpin D, Charlton H \& Gordon S 1984 The mononuclear phagocyte system of the mouse defined by immunohistochemical localization of antigen F4/80: macrophages of endocrine organs. PNAS 81 4174-4177. (doi:10.1073/pnas.81.13.4174)

Itoh M, Yano A, Li X, Miyamoto K \& Takeuchi Y 1999 Limited uptake of foreign materials by resident macrophages in murine ovarian tissues. Journal of Reproductive Immunology 43 55-66. (doi:10.1016/S01650378(99)00004-2)

Jeruss JS \& Woodruff TK 2009 Preservation of fertility in patients with cancer. New England Journal of Medicine 360 902-911. (doi:10.1056/ NEJMra0801454)

Katabuchi H, Suenaga Y, Fukumatsu Y \& Okamura H 1997 Distribution and fine structure of macrophages in the human ovary during the menstrual cycle, pregnancy and menopause. Endocrine Journal 44 785-795. (doi:10.1507/endocrj.44.785)

Kent J \& Ryle M 1975 Histochemical studies on three gonadotrophinresponsive enzymes in the infantile mouse ovary. Journal of Reproduction and Fertility 42 519-536. (doi:10.1530/jrf.0.0420519)

Kirsch TM, Friedman AC, Vogel RL \& Flickinger GL 1981 Macrophages in corpora lutea of mice: characterization and effects on steroid secretion. Biology of Reproduction 25 629-638. (doi:10.1095/biolreprod25.3.629)

Kirsch TM, Vogel RL \& Flickinger GL 1983 Macrophages: a source of luteotropic cybernins. Endocrinology 113 1910-1912. (doi:10.1210/ endo-113-5-1910)

Kreeger PK, Deck JW, Woodruff TK \& Shea LD 2006 The in vitro regulation of ovarian follicle development using alginate-extracellular matrix gels. Biomaterials 27 714-723. (doi:10.1016/j.biomaterials.2005.06.016)

Lenie S, Cortvrindt R, Adriaenssens T \& Smitz J 2004 A reproducible twostep culture system for isolated primary mouse ovarian follicles as single functional units. Biology of Reproduction 71 1730-1738. (doi:10.1095/ biolreprod.104.028415)

Li XQ, Itoh M, Yano A, Xie Q, Miyamoto K \& Takeuchi Y 1998 Distribution of F4/80-positive cells in developing ovaries in the mouse. Archives of Histology and Cytology 61 353-360. (doi:10.1679/aohc.61.353)

Liu YX \& Hsueh AJ 1986 Synergism between granulosa and thecainterstitial cells in estrogen biosynthesis by gonadotropin-treated rat ovaries: studies on the two-cell, two-gonadotropin hypothesis using steroid antisera. Biology of Reproduction 35 27-36. (doi:10.1095/ biolreprod35.1.27)

Liu J, Van der Elst J, Van den Broecke R \& Dhont M 2001 Live offspring by in vitro fertilization of oocytes from cryopreserved primordial mouse follicles after sequential in vivo transplantation and in vitro maturation. Biology of Reproduction 64 171-178. (doi:10.1095/biolreprod64.1.171)

Magoffin DA 2002 The ovarian androgen-producing cells: a 2001 perspective. Reviews in Endocrine \& Metabolic Disorders 3 47-53. (doi:10.1023/A:1012700802220)

Murray AA, Gosden RG, Allison V \& Spears N 1998 Effect of androgens on the development of mouse follicles growing in vitro. Journal of Reproduction and Fertility 113 27-33. (doi:10.1530/jrf.0.1130027)

Nathan CF 1987 Secretory products of macrophages. Journal of Clinical Investigation 79 319-326. (doi:10.1172/JCl112815)

O'Brien MJ, Pendola JK \& Eppig JJ 2003 A revised protocol for in vitro development of mouse oocytes from primordial follicles dramatically improves their developmental competence. Biology of Reproduction $\mathbf{6 8}$ 1682-1686. (doi:10.1095/biolreprod.102.013029) 
Otala M, Makinen S, Tuuri T, Sjoberg J, Pentikainen V, Matikainen T \& Dunkel L 2004 Effects of testosterone, dihydrotestosterone, and 17beta-estradiol on human ovarian tissue survival in culture. Fertility and Sterility 82 (Supplement 3) 1077-1085. (doi:10.1016/j.fertnstert.2004. 06.032)

Paavola LG 1979 The corpus luteum of the guinea pig, IV. Fine structure of macrophages during pregnancy and postpartum luteolysis, and the phagocytosis of luteal cells. American Journal of Anatomy 154 337-364. (doi:10.1002/aja.1001540304)

Pangas SA, Saudye H, Shea LD \& Woodruff TK 2003 Novel approach for the three-dimensional culture of granulosa cell-oocyte complexes. Tissue Engineering 9 1013-1021. (doi:10.1089/107632703 322495655)

Paranko J \& Pelliniemi LJ 1992 Differentiation of smooth muscle cells in the fetal rat testis and ovary: localization of alkaline phosphatase, smooth muscle myosin, F-actin, and desmin. Cell and Tissue Research 268 521-530. (doi:10.1007/BF00319159)

Petrovska M, Dimitrov DG \& Michael SD 1996 Quantitative changes in macrophage distribution in normal mouse ovary over the course of the estrous cycle examined with an image analysis system. American Journal of Reproductive Immunology 36 175-183.

Picton HM, Harris SE, Muruvi W \& Chambers EL 2008 The in vitro growth and maturation of follicles. Reproduction 136 703-715. (doi:10.1530/ REP-08-0290)

Polan ML, Loukides J, Nelson P, Carding S, Diamond M, Walsh A \& Bottomly K 1989 Progesterone and estradiol modulate interleukin-1 beta messenger ribonucleic acid levels in cultured human peripheral monocytes. Journal of Clinical Endocrinology and Metabolism 69 1200-1206. (doi:10.1210/jcem-69-6-1200)

Polec A, Tanbo T \& Fedorcsak P 2009 Cellular interaction regulates interleukin-8 secretion by granulosa-lutein cells and monocytes/macrophages. American Journal of Reproductive Immunology 61 85-94. (doi:10.1111/j.1600-0897.2008.00668.x)

Rinaudo M 2008 Main properties and current applications of some polysaccharides as biomaterials. Polymer International 57 397-430. (doi:10.1002/pi.2378)

Short RV 1962 Steroids in the follicular fluid and the corpus luteum of the mare. A 'two-cell type' theory of ovarian steroid synthesis. Journal of Endocrinology 24 59-63. (doi:10.1677/joe.0.0240059)

Simon C, Frances A, Piquette G \& Polan ML 1994 Immunohistochemical localization of the interleukin-1 system in the mouse ovary during follicular growth, ovulation, and luteinization. Biology of Reproduction 50 449-457. (doi:10.1095/biolreprod50.2.449)

Smitz J, Dolmans MM, Donnez J, Fortune JE, Hovatta O, Jewgenow K, Picton HM, Plancha C, Shea LD, Stouffer RL et al. 2010 Current achievements and future research directions in ovarian tissue culture, in vitro follicle development and transplantation: implications for fertility preservation. Human Reproduction Update 16 395-414. (doi:10.1093/ humupd/dmp056)
Takaya R, Fukaya T, Sasano H, Suzuki T, Tamura M \& Yajima A 1997 Macrophages in normal cycling human ovaries; immunohistochemical localization and characterization. Human Reproduction 12 1508-1512. (doi:10.1093/humrep/12.7.1508)

Tingen CM, Bristol-Gould SK, Kiesewetter SE, Wellington JT, Shea L \& Woodruff TK 2009 Prepubertal primordial follicle loss in mice is not due to classical apoptotic pathways. Biology of Reproduction 81 16-25. (doi:10.1095/biolreprod.108.074898)

Van der Hoek KH, Maddocks S, Woodhouse CM, van Rooijen N, Robertson SA \& Norman RJ 2000 Intrabursal injection of clodronate liposomes causes macrophage depletion and inhibits ovulation in the mouse ovary. Biology of Reproduction 62 1059-1066. (doi:10.1095/ biolreprod62.4.1059)

Vendola KA, Zhou J, Adesanya OO, Weil SJ \& Bondy CA 1998 Androgens stimulate early stages of follicular growth in the primate ovary. Journal of Clinical Investigation 101 2622-2629. (doi:10.1172/JCI2081)

West ER, Xu M, Woodruff TK \& Shea LD 2007 Physical properties of alginate hydrogels and their effects on in vitro follicle development. Biomaterials 28 4439-4448. (doi:10.1016/j.biomaterials.2007.07.001)

West-Farrell ER, Xu M, Gomberg MA, Chow YH, Woodruff TK \& Shea LD 2009 The mouse follicle microenvironment regulates antrum formation and steroid production: alterations in gene expression profiles. Biology of Reproduction 80 432-439. (doi:10.1095/biolreprod.108.071142)

Woodruff TK \& Shea LD 2007 The role of the extracellular matrix in ovarian follicle development. Reproductive Sciences 14 6-10. (doi:10.1177/ 1933719107309818)

Xu M, Kreeger PK, Shea LD \& Woodruff TK 2006a Tissue-engineered follicles produce live, fertile offspring. Tissue Engineering 12 2739-2746. (doi:10.1089/ten.2006.12.2739)

Xu M, West E, Shea LD \& Woodruff TK 2006b Identification of a stagespecific permissive in vitro culture environment for follicle growth and oocyte development. Biology of Reproduction 75 916-923. (doi:10. 1095/biolreprod.106.054833)

Xu M, Barrett SL, West-Farrell E, Kondapalli LA, Kiesewetter SE, Shea LD \& Woodruff TK 2009a In vitro grown human ovarian follicles from cancer patients support oocyte growth. Human Reproduction 24 2531-2540. (doi:10.1093/humrep/dep228)

Xu M, West-Farrell ER, Stouffer RL, Shea LD, Woodruff TK \& Zelinski MB $2009 \mathrm{~b}$ Encapsulated three-dimensional culture supports development of nonhuman primate secondary follicles. Biology of Reproduction $\mathbf{8 1}$ 587-594. (doi:10.1095/biolreprod.108.074732)

Yang MY \& Fortune JE 2006 Testosterone stimulates the primary to secondary follicle transition in bovine follicles in vitro. Biology of Reproduction 75 924-932. (doi:10.1095/biolreprod.106.051813)

Received 24 November 2010

First decision 27 January 2011

Accepted 9 March 2011 